\title{
Investigating Mechanical Properties of Carbon Glass Jute Fibre based Composite
}

\author{
Sami Hamid ${ }^{1}$, Abhishek Thakur ${ }^{2}$ \\ ${ }^{1}$ M.Tech. Scholar,Universal Group of Institutions Lalru \\ ${ }^{2}$ Assistant Professor, Universal Group of Institutions, Lalru
}

\begin{abstract}
Hybrid composites are made by combining natural and synthetic fibers with an effective matrix, which usually means they've received additional strengthening, such as epoxy, to create the additional material properties you can't obtain on their own. To attain the desirable tensile modulus, compressive modulus, and so on, a fiber composite needs to be added to the FRP (Fiber Reinforced Ploymer). Polymer matrix composites are light and cost-effective to manufacture, but they still friendly to the environment and have viable applications, which is why they are often used in various commercial applications. Unidirectional fibers and bidirectionally reinforced with epoxy (SikaDur is a composite medium) carbon fibers are the two-way reinforced with unidirectional (use unidirectional) Before we developed tests procedures for preparing the test specimens, the testing lab implemented the layup method according to ASTM standards. Ten separate stacking sequences were tested and four different intensity sequences were used in testing the compressive structures according to ASTM D15. The results of the study indicate that hybridization helps natural fiber-reinforced polymer compositesto increase their mechanical properties We would use natural fibers rather than synthetic ones since the natural ones make comparable strength when hybridized with synthetic ones.
\end{abstract}

Keywords:Hybrid composites, Carbon Fibre, Fibre reinforced polymers, Jute fibre

\section{Introduction:}

Synthetic fibres used as reinforcements in composite materials such as glass, carbon and Kevlar fibres are commonly used in automotive and aerospace industries that need high strength and stiffness to weight ratio. Composites reinforced with such fibres, particularly glass fibres, have detrimental impacts on the environment and human's health especially at the end of their service life as they are not biodegradable materials. On the other hand, the common natural fibres with plant-based such as bamboo, sugar palm, kenaf, jute, sisal, hemp and flax are considered eco-friendly, low cost, low density, abundant and renewable [1,2]. These fibres have been recently used to reinforce the composites instead of using synthetic fibres. Natural fibre composites exhibit lower elastic modulus, lower tensile strength, and higher moisture absorption compared to composites reinforced with synthetic fibres such as glass [2]. Other disadvantages of natural fibres include their higher variability of mechanical properties and weak adhesion with polymeric matrices due to fibre's hydrophilic nature, relatively higher undulation (crimp), higher lumen (cavity) existence, and poor wettability [3, 4]. Concerning mechanical properties, the tensile strengths of these fibres are only $20 \%-50 \%$ of that of E-glass fibres [5]. Therefore, incorporation or hybridisation of different types of fibres in the composite could meet the need. The hybridisation of proper synthetic and natural fibres in a single matrix was mainly used to supplement any lack in a certain characteristic of one fibre by other fibre $[2,6]$. The natural/synthetic hybrid fibre reinforced composites could offer reasonable mechanical properties and balanced costs compared with a composite reinforced with an individual fibre material [7]. 
Hybrid composites made from jute-glass fibres/epoxy resin system may potentially be used in biomedical applications such as bone fracture plate instead of bone metallic implants, sport applications such as tennis rackets and bicycle's frame. These applications are exposed to fatigue loadings during their service life. Fatigue behaviour of different natural fibre reinforced composites was well investigated by many researchers [8-12]. However, few studies regarding fatigue life of natural/synthetic hybrid fibre reinforced composites have been published.

Carbon fiber is mostly preferred where lightness and high stiffness are required. However, it has a lower impact strength compared to the E-glass fiber and conventional steel alloys. Impact strength and ultimate strain of carbon-reinforced composites are mostly improved by adding E-glass or Kevlar fiber to the composite. Carbon fiber-reinforced composites are mainly used in aerospace applications [19, 20]. Comparative mechanical properties of these fibers are given in Table 1. In the literature, it is seen that jute fiber is mostly hybridized with E-glass fiber. In one of the studies, Gujjala et al. searched the effect of hybridizing E-glass fabric with jute fabric and of stacking sequence on the density, tensile, flexural and interlaminar shear properties of woven jute/glass fiber hybrid composites. They prepared the samples by hand lay-up process and they preferred epoxy resin as matrix material. According to the results, the maximum interlaminar shear strength and tensile strength were obtained with the composite prepared with E-glass fabric at extreme layers; however, the maximum flexural strength was obtained with composite GJGJ which has a fabric stacking sequence of “glass-jute-glass-jute” [22]. Gowda et al. studied the mechanical properties (tensile strength, compressive strength, flexural strength, impact strength, in-plane shear strength, inter-laminar shear strength and hardness) of woven jute fabricreinforced composites that were produced by hand lay-up technique.

Table 1. Comparison of properties [21]

\begin{tabular}{|l|l|l|l|}
\hline & Density $(\mathrm{g} / \mathrm{cm} 3)$ & Elastic Modulus $(\mathrm{GPa})$ & Tensile Strength $(\mathrm{GPa})$ \\
\hline Fiber & 1.45 & $10-32$ & $0.45-0.55$ \\
\hline Jute E glass & 2.60 & 73 & $1.80-2.70$ \\
\hline Carbon & 1.80 & 260 & $3.50-5.00$ \\
\hline
\end{tabular}

\section{Material and Methods}

Unidirectional E-glass fiber of 430 GSM having fabric design thickness of $0.172 \mathrm{~mm}$ and fiber density of $2.56 \mathrm{~g} / \mathrm{cm} 3$ manufactured by SIKAWRAP was used to prepare specimens. The material i.e. glass fiber was supplied by S N Associates, Delhi.

Table 2 Properties of glass fiber[28]

\begin{tabular}{|c|c|c|c|c|}
\hline \multirow{2}{*}{ Material } & \multicolumn{4}{|c|}{ Major properties } \\
\cline { 2 - 5 } & $\begin{array}{c}\text { Density } \\
(\mathrm{gm} / \mathrm{cc})\end{array}$ & $\begin{array}{c}\text { Modulus } \\
\left(\mathrm{N} / \mathrm{mm}^{2}\right)\end{array}$ & $\begin{array}{c}\text { Failure strain } \\
(\%)\end{array}$ & $\begin{array}{c}\text { Strength } \\
\left(\mathrm{N} / \mathrm{mm}^{2}\right)\end{array}$ \\
\hline Glass fiber & 2.56 & 76000 & 2.8 & 3400 \\
\hline
\end{tabular}

Unidirectional carbon fiber of grade 450C manufactured by SIKAWRAP was purchased by S N Associates, Delhi. The fabric thickness of the carbon fiber was $0.255 \mathrm{~mm}$ and fiber density was 1.82 $\mathrm{g} / \mathrm{cm} 3$. 
Table 3 Properties of Carbon fiber[29]

\begin{tabular}{|c|c|c|c|c|}
\hline \multirow{2}{*}{ Material } & \multicolumn{4}{|c|}{ Major properties } \\
\cline { 2 - 5 } & $\begin{array}{c}\text { Density } \\
(\mathrm{gm} / \mathrm{cc})\end{array}$ & $\begin{array}{c}\text { Modulus } \\
\left(\mathrm{N} / \mathrm{mm}^{2}\right)\end{array}$ & $\begin{array}{c}\text { Failure strain } \\
(\%)\end{array}$ & $\begin{array}{c}\text { Strength } \\
\left(\mathrm{N} / \mathrm{mm}^{2}\right)\end{array}$ \\
\hline Carbon Fiber & 1.82 & 230000 & 1.7 & 4000 \\
\hline
\end{tabular}

\subsection{Jute fiber}

Bidirectional Jute fiber was purchased by S N Associates, Delhi. The fabric thickness of the Jute fiber was $.8 \mathrm{~mm}$ and fiber density was $1.4 \mathrm{~g} / \mathrm{cm} 3$.

Table 4 Properties of Jute fiber

\begin{tabular}{|c|c|c|c|c|}
\hline \multirow{2}{*}{ Material } & \multicolumn{4}{|c|}{ Major properties } \\
\cline { 2 - 5 } & $\begin{array}{c}\text { Density } \\
(\mathrm{gm} / \mathrm{cc})\end{array}$ & $\begin{array}{c}\text { Modulus } \\
\left(\mathrm{N} / \mathrm{mm}^{2}\right)\end{array}$ & $\begin{array}{c}\text { Failure strain } \\
(\%)\end{array}$ & $\begin{array}{c}\text { Strength } \\
\left(\mathrm{N} / \mathrm{mm}^{2}\right)\end{array}$ \\
\hline $\begin{array}{c}\text { Jute } \\
\text { Fiber[30][31][32] }\end{array}$ & 1.4 & 30000 & $3.6-4.2$ & $400-800$ \\
\hline
\end{tabular}

\subsection{SikaDur Epoxy 330IN}

Two-part epoxy (A+B) manufactured by SIKA India was used as the matrix material for the sample preparation was purchased from S N Associates, Delhi. The epoxy was two part Saturate- Hardener mixture in a ratio of 80:20 by weight.

Table 5 Properties of Epoxy Resign[33]

\begin{tabular}{|c|c|c|c|c|}
\hline \multirow{2}{*}{ Material } & \multicolumn{4}{|c|}{ Major properties } \\
\cline { 2 - 5 } & Density & $\begin{array}{c}\text { Modulus } \\
\left(\mathrm{N} / \mathrm{mm}^{2}\right)\end{array}$ & $\begin{array}{c}\text { Failure strain } \\
(\%)\end{array}$ & $\begin{array}{c}\text { Strength } \\
\left(\mathrm{N} / \mathrm{mm}^{2}\right)\end{array}$ \\
\hline Epoxy & 1.3 & 3500 & 0.9 & 30 \\
\hline
\end{tabular}




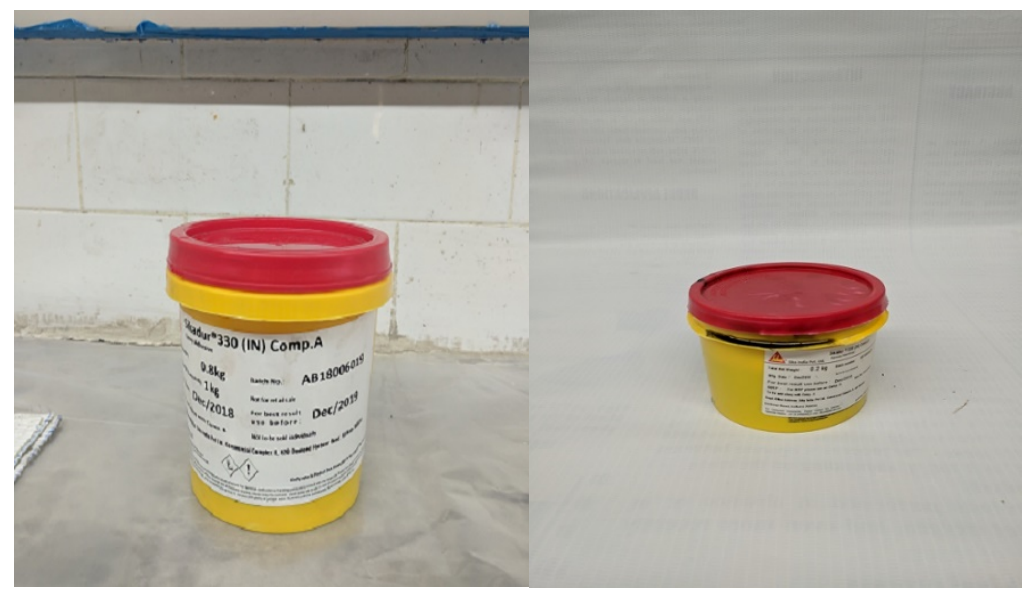

Fig.1 Saturant part of epoxy(Comp. A)Fig. 2 Hardenar part of epoxy(Comp. B)

According to the ASTM D3039/D3039M-17 the standard sample geometry is given in table below:

Table 6 Tensile specimen geometry recommendation according to ASTM D3039M-17

\begin{tabular}{|c|c|c|c|}
\hline Fiber orientation & Width (mm) & Overall length (mm) & Tab length(mm) \\
\hline 00 Unidirectional & 15 & 250 & 56 \\
\hline 900 Unidirectional & 25 & 175 & 25 \\
\hline
\end{tabular}

For my experiment purpose the fiber direction was 00 unidirectional so the geometry was in accordance with the standards.

\subsubsection{ASTM Standard used}

This testing method is used as a testing procedure for the determination of the mechanical properties of the rigid plastics, including high modulus composites, when loaded in compression at relatively low uniform rates of straining. The standard speed of testing shall be $1.3 \pm 0.3 \mathrm{~mm}(0.050 \pm 0.010 \mathrm{in}$. $) / \mathrm{min}$ according to this standard.

\subsubsection{Sample geometry[35]}

According to the standard ASTM D695-15 the test sample for the compression testing should be of bar shaped and dimensions of the sample should be $12.7 \mathrm{~mm} \times 12.7 \mathrm{~mm} \times 25.4 \mathrm{~mm}$. For the testing the bar shaped samples are made with four possible combinations such as the desired strength due to hybridization of fibers should be observed and compared with each other.

The four possible stacking sequences were:

GGGJJJ....

CCCJJJ....

JJJJJJ.... 


\section{GJCGJC....}

In the above samples G-glass fiber, C- Carbon fiber and J-Jute fiber. Layers were set up on one another until desired thickness of $12.7 \mathrm{~mm}$.

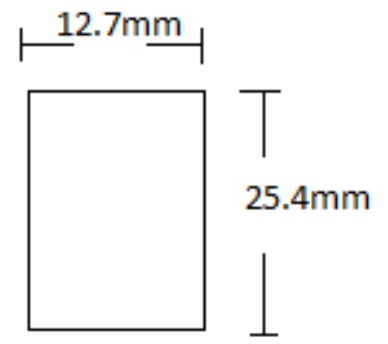

Front view

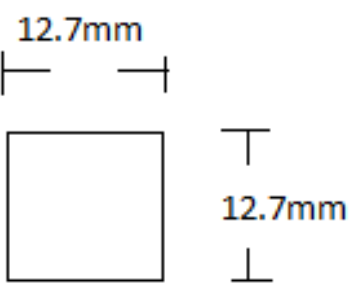

Top View

Fig. 3 Specimen dimensions for compressive test

For the preparation of the samples two moulds were prepared for the tensile specimen the dimension of the mould was $300 \mathrm{~mm} \times 100 \mathrm{~mm}$ and for the compressive test specimen mould dimension was $50 \mathrm{~mm} \times 100 \mathrm{~mm}$. Both the moulds were having the flat surface with no boundaries so that during pressing of sheet for removal and uniform spreading of epoxy there will be no difficulty.

After fixing respective fiber sheet according to test sample and stacking order on the mould, the two-part epoxy mixture was mixed with each other in a ratio of 80:20 according to the prescription on the manual for better results. The weight measurement is done by using a weighing machine. After taking proper ratio of epoxy and hardener in a container, they are mixed well using stirrer.

\subsection{Setting of various layers of fibers according to sample requirement}

After preparation of epoxy, epoxy resin solution was applied on the first layer of the specimen and the specimen then left for 24 hours to let it harden, after 24 hours the test specimen layer was flipped upside down and again epoxy resin solution was applied with the help of steel scrappers and another layer of desired fiber was applied. After this, the excess epoxy solution between the fiber layers was removed with the help of a roller by gently rolling over the specimen and by this air trapped between the layers also removed. This process of applying the epoxy solution, fiber layer and roll pressing was repeated until the desired thickness of the specimen reached. After the specimen reached the desired thickness it was left for curing for one week at room temperature.

\section{Results}

During tensile testing maximum number of samples failed due to fiber cracking and fiber pull from the matrix. The mode of failure was brittle in nature with nonlinear graph and no significant visible yield stress and strain points in the graph so the properties like yield stress and yield strain were obtained by $0.2 \%$ offset method.The samples which are considered for the results are failed from lateral gage failure with significant fiber pull up and matrix cracking. The samples with carbon fibers failed with less fiber pull and elongation and the samples with jute as main reinforcement have maximum strain 
Table 7 Average Tensile strength obtained during the tensile test

\begin{tabular}{|c|c|c|c|c|c|c|c|c|c|c|}
\hline \multirow{2}{*}{ Property } & \multicolumn{9}{|c|}{ Combinations } \\
\cline { 2 - 11 } & GJC & GCG & GJG & CJC & CGC & JCJ & JGJ & GGG & CCC & JJJ \\
\hline Tensile & & & & & & & & & & \\
Strength & 65.46 & 91.53 & 60.75 & 68.63 & $\begin{array}{c}107.8 \\
4\end{array}$ & 50.80 & 43.25 & 81.71 & $\begin{array}{c}112.1 \\
8\end{array}$ & 40.54 \\
$(\mathrm{MPa})$ & & & & & & & & & & \\
\hline
\end{tabular}

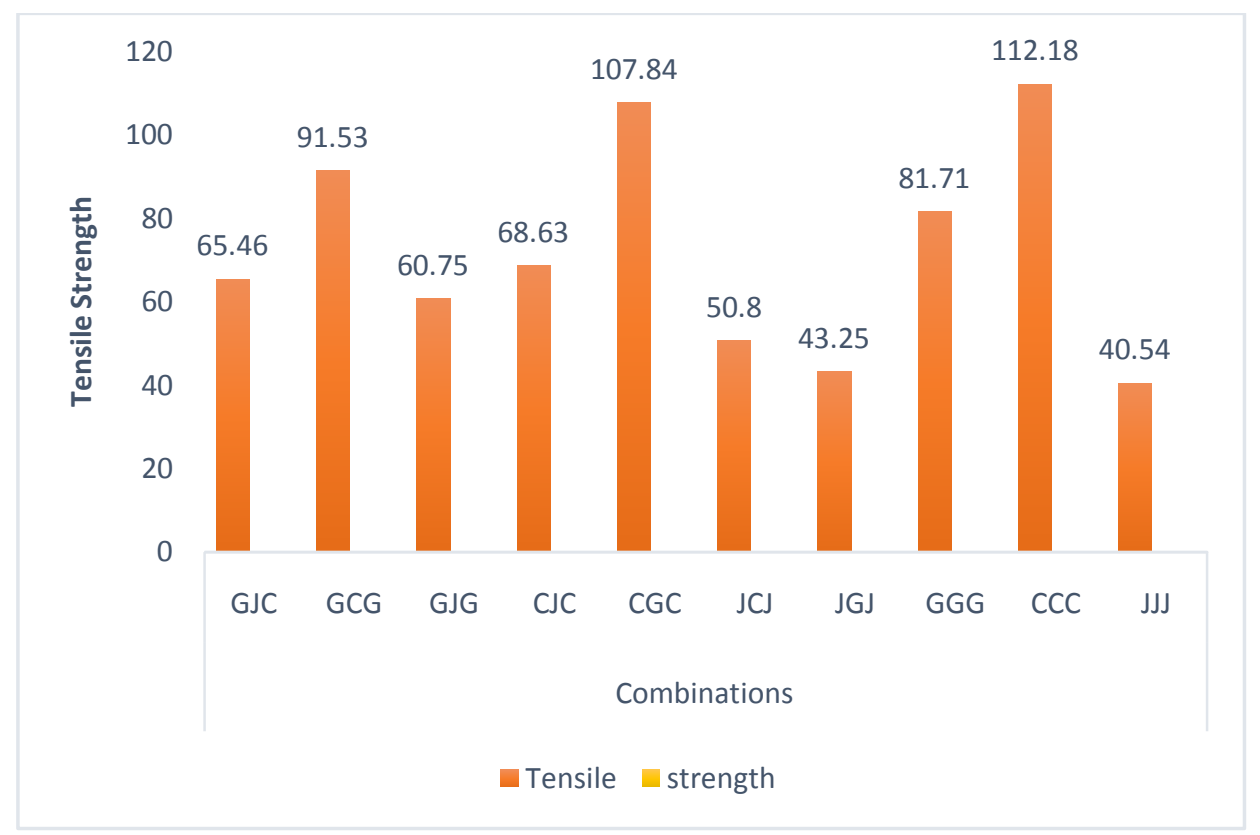

Fig.4 Bar graph showing tensile strength of different combinations

From the compression test properties such as modulus of elasticity in compression, yield stress, peak load, and stress-strain data are obtained for each stacking sequence for each sample and average properties were obtained. The data charts are prepared to understand the behavior of composite failure and for a comparative study.

Table 8. Compressive strength obtained during the compression test

\begin{tabular}{|c|c|c|c|c|c|}
\hline \multirow{2}{*}{ Property } & \multirow{2}{*}{ Units } & \multicolumn{3}{|c|}{ Combinations } \\
\cline { 3 - 6 } & & GGG & CCC & JJJ & GJC \\
\hline Compressive Strength & MPa & 258.56 & 225.86 & 99.26 & 214.23 \\
\hline
\end{tabular}




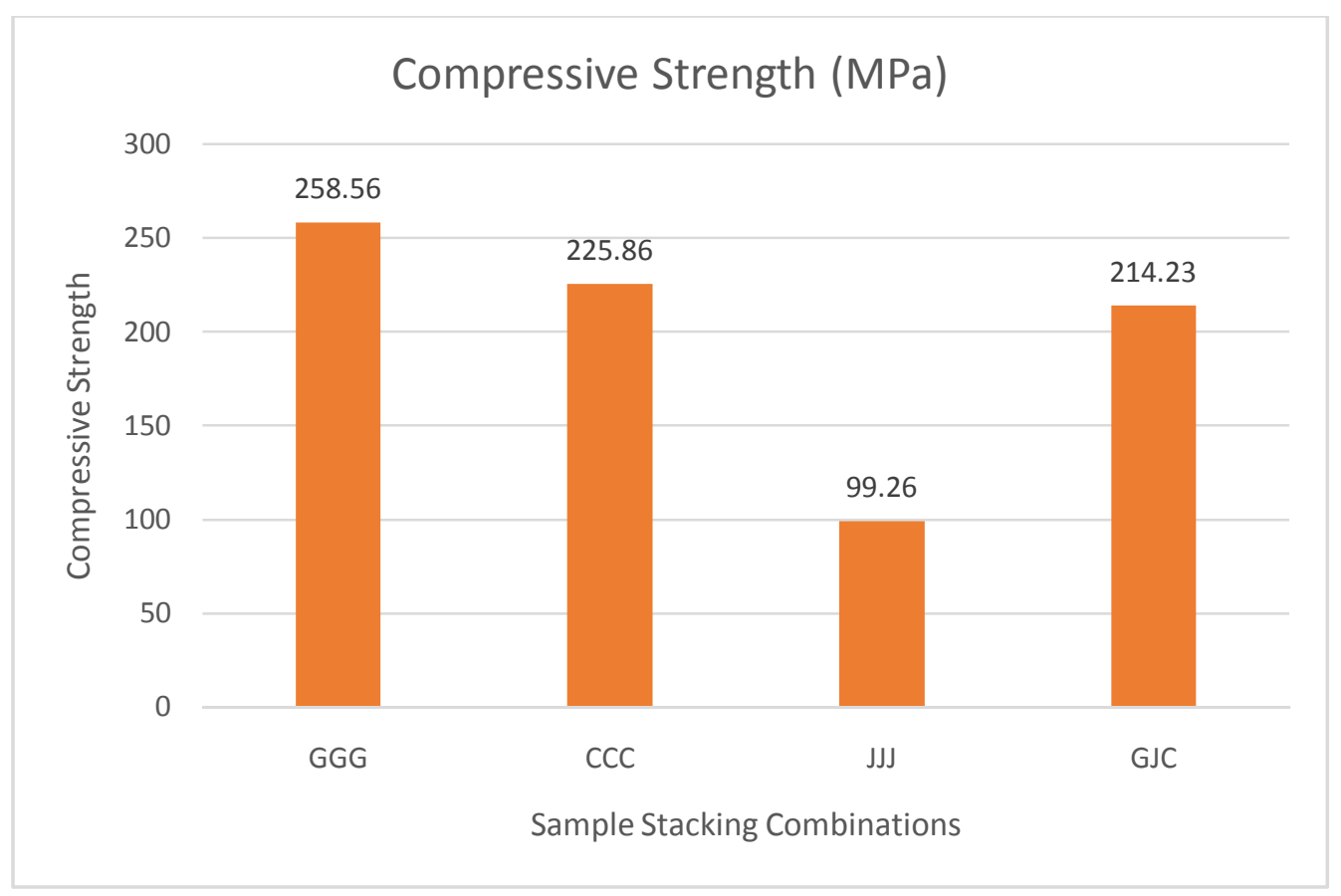

Fig.5. Bar graph showing compressive strength of different combinations

\section{Conclusions}

During tensile testing it is seen that carbon fiber composites offer maximum strength and jute fiber composites offer least strength. Due to brittleness of carbon fiber composites having more carbon fiber lamina have less yield strain as compared to composites which have more jute lamina. In all the hybrid composite samples which contain glass, carbon and jute as reinforcement, the composites which are having more carbon fiber lamina as reinforcement have more strength and strength decreased as jute fiber reinforcement increased in glass and/or carbon reinforcement composites.During tensile testing it is seen that the composites in which jute fiber lamina was in between the carbon and glass fiber lamina offered best overall characteristics out of all the hybrid composites made from glass, carbon and jute as reinforcement material.

By using jute with carbon and glass fiber there is increment of, 6.684\% in strength with two jutes and one glass layer, $25.30 \%$ with one carbon and two jute layers and $50.21 \%$ strength increment with one jute and two glass layers during tensile testing.In tensile testing maximum strength is noted in the hybrid composite with CGC stacking sequence which was close to CCC stacking sequence but having a cost $19.44 \%$ less than CCC stacking sequence.GJC sample which is having $48.15 \%$ cost reduction as compared to CCC sample and having strength $61.47 \%$ more than JJJ sample. 


\section{References}

[1] Gujjala R, Ojha S, Acharya S Kand Pal SK,2014 ,Mechanical properties of woven jute-glass hybrid-reinforced epoxy composite. J. Compos. Mater. 48 3445-55

[2] Dong C, 2018, Review of natural fibre-reinforced hybrid composites J. Reinf. Plast. Compos. 37 331-48

[3] Gassan J and Bledzki AK, 1997, The influence of fiber-surface treatment on the mechanical properties of jute-polypropylene composites. Compos. Part A Appl. Sci. Manuf. 28 1001-5

[4] Kureemun U, Ravandi M, Tran LQN, TeoWS, Tay T E and LeeHP, 2018, Effects of hybridization and hybrid fibre dispersion on the mechanical properties of woven flax-carbon epoxy at low carbon fibre volume fractions Compos. Part B Eng. 134 28-38

[5] Gassan J and Bledzki AK, 1999, Possibilities for improving the mechanical properties of jute/epoxy composites by alkali treatment of fibres Compos. Sci. Technol. 59 1303-9

[6] Safri SNA, Sultan MT H, Saba N and Jawaid M , 2018, Effect of benzoyl treatment on flexural and compressive properties of sugar palm/glass fibres/epoxy hybrid composites Polym. Test 71 362-369

[7] Safri SNA, SultanMT H, JawaidMand JayakrishnaK, 2018, Impact behaviour of hybrid composites for structural applications: a review Compos. Part B Eng. 133 112-21

[8] Towo AN and Ansell MP 2008 Fatigue evaluation and dynamic mechanical thermal analysis of sisal fibre-thermosetting resin composites Compos. Sci. Technol. 68 925-32

[9] Liang S, Gning P B and Guillaumat L, 2012, A comparative study of fatigue behaviour of flax/epoxy and glass/epoxy composites Compos. Sci. Technol. 72 535-43

[10] Shahzad A and IsaacDH, 2014, Fatigue properties of hemp and glass fiber composites Polym. Compos. 35 1926-34

[11] Abdullah AH and Mat MF, 2015, Fatigue life of arenga pinnata/epoxy composites Adv. Mater. Res. $1102103-6$

[12] Ismail AE and Abdul Aziz MA, 2015, Fatigue strength of woven kenaf fiber reinforced composites IOP Conf. Ser.: Mater. Sci. Eng. 3rd Int. Conf. Mech. Eng. Res. (ICMER 2015) 100 (012037)

[13] Pandya KS, Veerraju C and Naik NK, 2011,. Hybrid composites made of carbon and glass woven fabrics under quasi-static loading. Mater Des ; 32: 4094-4099.

[14] Sevkat E., 2011, Finite element analysis of functionally hybridized carbon/glass composite shafts. J Reinf Plast Compos ; 33: 1226-1236.

[15] Alves C, Dias APS, Diogo AC, et al. Eco-composite: The effects of the jute fiber treatment on the mechanical and environmental performance of the composite materials. J Comp Mater; 45: 573-589.

[16] Gowda TM, Naidu ACB and Chhaya R, 2010,. Some mechanical properties of untreated jute fabric-reinforced polyester composites. Compos Part A 1999; 30: 277-284.

[28] P. Data, “SikaWrap ${ }^{\circledR}-430$ G,” pp. 2-4, 2014.

[29] C. Sikawrap, “SikaWrap ${ }^{\circledR}-450$ C,” pp. 2-5, 2014.

[30] P. Wambua, J. Ivens, and I. Verpoest, “Natural fibres: Can they replace glass in fibre reinforced plastics?,” Compos. Sci. Technol., vol. 63, no. 9, pp. 1259-1264, 2003.

[31] M. Ramesh, K. Palanikumar, and K. H. Reddy, “Comparative evaluation on properties of hybrid glass fiber-sisal/jute reinforced epoxy composites,” Procedia Eng., vol. 51, no. NUiCONE 2012, pp. 745-750, 2013.

[32] M. Ramesh, K. Palanikumar, and K. H. Reddy, "Mechanical property evaluation of sisal-jute-glass fiber reinforced polyester composites,” Compos. Part B Eng., vol. 48, pp. 1-9, 2013.

[33] P. D. Sheet, “Sikadur ${ }^{\circledR}-330$ (IN),” vol. 330, pp. 1-5, 2017. 
[34] “ASTM D3039 / D3039M-17, Standard Test Method for Tensile Properties of Polymer Matrix Composite Materials, ASTM International, West Conshohocken, PA, 2017.” [Online]. Available: https://www.astm.org/Standards/D3039. [Accessed: 05-Jul-2019].

[35] “ASTM D695-15, Standard Test Method for Compressive Properties of Rigid Plastics, ASTM International, West Conshohocken, PA, 2015.” 